\title{
A CONTRIBUIÇÃO DE INTERVENÇÃO NO DOMÍNIO ECONÔMICO - CIDE COMO EFETIVO INSTRUMENTO DE PROTEÇÃO AO MEIO AMBIENTE
}

INTERVENTION CONTRIBUTION IN ECONOMIC DOMAIN - CIDE AS

EFFECTIVE PROTECTION INSTRUMENT FOR THE ENVIRONMENT

\author{
${ }^{1}$ Amanda Madeira Reis \\ ${ }^{2}$ Celso Antonio Pires Ferreira
}

\section{Resumo}

Diante da observância da finitude dos recursos naturais, a humanidade vem percebendo a necessidade de harmonizar o desenvolvimento econômico e a proteção ambiental. A partir dessa percepção, surge o conceito de desenvolvimento sustentável. A Constituição Federal de 1988, seguindo essa noção, aponta ser responsabilidade da sociedade e do Estado a manutenção de um meio ambiente sadio. Para tanto, ao Poder Público cabe a adoção de políticas públicas para proteção do meio ambiente a partir da tributação. Assim, o trabalho apresenta tributação ambiental, especialmente a contribuição de intervenção no domínio econômico, como efetivo instrumento de proteção ao meio ambiente.

Palavras-chave: Desenvolvimento Sustentável; Tributação Ambiental; CIDE.

\begin{abstract}
On compliance with the finiteness of natural resources, humanity is realizing the need to harmonize economic development and environmental protection. From this awareness, comes the concept of sustainable development. The Federal Constitution of 1988, following this notion, aims to be the responsibility of society and the state to maintain a healthy environment. Therefore, the Government is up to adoption of public policies for environmental protection from taxation. Thus, the work presents environmental taxation, especially the intervention contribution in the economic domain, as an effective instrument to protect the environment.
\end{abstract}

Keywords: Sustainable development; Environmental taxation; CIDE.

\footnotetext{
1 Mestre Direito pela Universidade Católica de Brasilia, UCB - Brasilia - DF, (Brasil). Professora de Direito Processual Civil e Trabalhista e Direito do Trabalho no Centro de Ensino Superior Vale do Parnaíba, CESVALE - PB, (Brasil). E-mail: amandamadeirareis@gmail.com

${ }^{2}$ Mestre Direito pela Universidade Católica de Brasilia, UCB - Brasilia - DF, (Brasil).

E-mail:celsopires@gmail.com
} 


\section{INTRODUÇÃO}

Nos últimos anos, a humanidade vem tomando consciência acerca da finitude dos recursos da natureza. Vive-se um tempo em que não cabe mais a ideia de inesgotabilidade dos bens extraídos do meio ambiente. A questão que se apresenta é como harmonizar a necessidade de manutenção do equilíbrio ambiental no seio de uma sociedade capitalista, que almeja sempre o crescimento econômico, visando o lucro.

É aqui que surge a necessidade de se apresentar o conceito de desenvolvimento sustentável, que, segundo o Relatório Brundtlant da Comissão Mundial sobre o Meio Ambiente e Desenvolvimento (ONU), de 1987, pode ser definido como aquele que atende às necessidades do presente sem comprometer a possibilidade de as gerações futuras atenderem suas próprias necessidades.

Esse relatório firmou uma nova tendência mundial, seguida inclusive pela Constituição Federal de 1988, que em seu art. 225 traz a previsão de que todos têm direito ao meio ambiente ecologicamente equilibrado, bem de uso comum do povo e essencial à sadia qualidade de vida, impondo-se ao Poder Público e à coletividade o dever de defendê-lo e preservá-lo para as presentes e futuras gerações.

Como se observa, a CF/88 atribui responsabilidade concorrente à sociedade e ao Estado pela manutenção de um meio ambiente sadio. Em relação à sociedade, pode-se dizer que essa responsabilidade demanda o alcance de uma consciência ecológica que, por sua vez, necessita que haja investimento no que se denomina educação ambiental.

Por outro lado, em consonância com aquele dispositivo constitucional, aponta-se, entre os instrumentos econômicos usados pelo Estado para a preservação do meio ambiente, o tributo.

O tributo ambiental deve ser vislumbrado como um instrumento de intervenção na atividade econômica, pela qual o Estado se vale para a constituição de uma cidadania ambiental que garanta uma proteção às gerações presentes e futuras. Sob um primeiro aspecto, o tributo ambiental se apresenta de fato como aquele sugere ou incentiva a adoção de atitudes ecologicamente equilibradas, por meio da instituição de incentivos fiscais em prol da sustentabilidade. Nesse foco, observa-se a presença do princípio ambiental da precaução, que, em linhas gerais, alicerça-se na possibilidade de evitar a deterioração ambiental.

Por outro lado, a tributação ambiental também tem fundamento no princípio do poluidor-pagador, impondo ao poluidor a responsabilidade pela reparação dos danos causados 
ao meio ambiente. Esse princípio busca evitar que a repercussão econômica da poluição, tida como o custo de sustentação do ambiente sadio, recaia sobre a coletividade. Ainda, caracteriza-se, como princípio atuante principalmente em momento posterior à ocorrência de prejuízos causados à coletividade.

A partir dessa lógica, o tributo recolhido aos cofres estatais possui destino certo: financiar os custos do Estado com a defesa ou, especialmente, com a recuperação do meio ambiente. Nesse sentido, o presente trabalho tem como objeto de estudo a contribuição de intervenção no domínio econômico incidente sobre os combustíveis, tributo adequado ao princípio do poluidor-pagador, cujo produto de sua arrecadação deverá ser destinado, dentre outros, ao financiamento de Programas de Infraestrutura de Transportes.

Pretende-se, assim, apresentar a contribuição de intervenção no domínio econômico incidente sobre os combustíveis - Cide combustíveis, como um efetivo instrumento de proteção ao meio ambiente.

\section{MEIO AMBIENTE E DESENVOLVIMENTO SUSTENTÁVEL}

Durante a revolução industrial, observa-se uma extrema confiança nas inovações tecnológicas e, paradoxalmente, uma crença na infinitude dos recursos naturais. Com o passar do tempo, a lógica que engendrava a Revolução Industrial, constituída pela técnica, pela ciência e pela sociedade de consumo, além de não conseguir alcançar o progresso almejado pelos países, trouxe consigo a escassez de recursos naturais, desequilíbrios econômicos e manutenção da pobreza (VILLAC, p. 46-47).

Primeiramente, há de se apontar que todos os habitantes do planeta mantém uma coexistência. Segundo Fritjof Capra (2005, p. 23):

\footnotetext{
Não existe nenhum organismo individual que viva no isolamento. Os animais dependem da fotossíntese das plantas para ter atendidas as suas necessidades energéticas; as plantas dependem do dióxido de carbono produzido pelos animais, bem como do nitrogênio fixado pelas bactérias em suas raízes; e todos juntos, vegetais, animais e microorganismos, regulam toda a biosfera e mantêm as condiçõos propícias à preservação da vida. [...]
}

De fato, os elementos da natureza não são todos passíveis de controle e intervenção humana, podendo ser apontados como exemplos os “recursos não renováveis e os renováveis 
que - utilizados com mais rapidez do que sua capacidade de recomposição - findam por colocar o homem diante de dilemas econômicos e ambientais" (VILLAC, p. 46-47).

Sobre a finitude dos recursos da natureza, o Professor José Afonso da Silva (2004, p. 28) pontua que:

\begin{abstract}
A ação predatória do meio ambiente natural manifesta-se de várias maneiras, quer destruindo os elementos que o compõem, como a derrubada das matas, quer contaminando-os com substâncias que lhes alterem a qualidade, impedindo seu uso normal, como se dá com a poluição do ar, das águas, do solo e da paisagem.
\end{abstract}

Essa ação predatória traz consigo a impossibilidade de que sejam previstos e circunscritos os riscos a serem por ela produzidos. Esses riscos que estão além do controle do ser humano são ínsitos ao contexto denominado por Beck (2010) como Sociedade de Risco.

Nesse sentido, vive-se um tempo em que não cabe mais a ideia de inesgotabilidade dos bens extraídos do meio ambiente. A questão que se apresenta é como harmonizar essa necessidade de manutenção do equilíbrio ambiental no seio de uma sociedade capitalista, que almeja sempre o crescimento econômico, visando o lucro.

É aqui que surge a necessidade de se apresentar o conceito de desenvolvimento sustentável. Nas palavras de Silva (2004, p. 26/27), desenvolvimento sustentável

[...] consiste na exploração equilibrada dos recursos naturais, nos limites da
satisfação das necessidades e do bem-estar da presente geração, assim como de sua
conservação no interesse das gerações futuras. Requer, como requisito
indispensável, um crescimento econômico que envolva equitativa redistribuição dos
resultados do processo produtivo e a erradicação da pobreza, de forma a reduzir as
disparidades nos padrões de vida e melhor atendimento da maioria da população. Se
o desenvolvimento não elimina a pobreza absoluta, não propicia um nível de vida
que satisfaça as necessidades essenciais da população em geral, ele não pode ser
qualificado de sustentável.

Segundo o Relatório Brundtlant da Comissão Mundial sobre o Meio Ambiente e Desenvolvimento (ONU), de 1987, pode-se definir desenvolvimento sustentável como aquele que atende às necessidades do presente sem comprometer a possibilidade de as gerações futuras atenderem suas próprias necessidades.

Esse relatório firmou uma nova tendência mundial, seguida inclusive pela Constituição Federal de 1988, que em seu art. 225 traz a previsão de que todos têm direito ao meio ambiente ecologicamente equilibrado, bem de uso comum do povo e essencial à sadia qualidade de vida, impondo-se ao Poder Público e à coletividade o dever de defendê-lo e preservá-lo para as presentes e futuras gerações. 
Essa preocupação do legislador em conferir status constitucional aos direitos ambientais justifica-se na medida em que a preservação da vida e a dignidade da pessoa humana - objetivo da $\mathrm{CF} / 88$ - só podem ser alcançadas dentro de um contexto ambiental equilibrado. De fato, a relação entre atividade econômica e meio ambiente deve se embasar na existência digna da pessoa, contribuindo os fatores ambientais para o bem-estar físico e psíquico do ser humano.

Nessa esteira de raciocínio, cabe registrar a lição do Professor Ingo Wolfgang Sarlet (2014, p. 11):

\begin{abstract}
Com a base na abordagem da proteção ambiental a partir da Teoria dos Direitos Fundamentais, identifica-se uma dimensão ecológica a conformar (juntamente as dimensões social, histórico-cultural etc.) o conteúdo normativo do princípio da dignidade da pessoa humana, bem como da correlata garantia do que passou a se designar de um mínimo existencial. A degradação ambiental e todos os demais riscos ecológicos (como, por exemplo, a contaminação química e o aquecimento global) que operam no âmbito das relações sociais (agora socioambientais!) contemporâneas comprometem significativamente o bem-estar individual e coletivo.
\end{abstract}

Ressalte-se que a CF/88, em seu art. 225 atribui responsabilidade concorrente à sociedade e ao Estado pela manutenção de um meio ambiente sadio. Nesse sentido, em relação à sociedade, pode-se dizer que essa responsabilidade demanda o alcance de uma consciência ecológica que, por sua vez, necessita que haja investimento no que se denomina educação ambiental. que trata do direito à educação ambiental. A CF/88, no inciso VI do $\S 1^{\circ}$ do seu art. 225, impõe ao Poder Público o dever de "promover a educação ambiental em todos os níveis de ensino e a conscientização pública para a preservação do meio ambiente".

Portanto, há de se investir na formação de uma consciência ambiental, de uma ação recíproca em torno de um objetivo comum que é o resguardo do desenvolvimento sustentável das atuais e futuras gerações. Aqui, são cabíveis as ponderações de James Lovelock (2006, p. 130):

O conceito de Gaia, um planeta vivo, é para mim a base essencial de um ambientalismo coerente e prático. Opõe-se à crença persistente de que a Terra é uma propriedade, um bem imóvel, a ser explorado em benefício da humanidade. Esta falsa crença de que somos donos da Terra, ou seus dirigentes, permite que nos declaremos a favor das políticas e programas ambientais, mas continuemos deixando as coisas como estão. Uma olhada em qualquer jornal financeiro confirma que nosso objetivo ainda é o crescimento e o desenvolvimento. Vibramos com qualquer nova descoberta de depósitos de gás ou petróleo e consideramos o aumento atual dos preços do petróleo um desastre potencial, e não um freio bem-vindo a poluição. Poucos, mesmo dentre os cientistas do clima e ecologistas, parecem perceber 
plenamente a gravidade potencial, ou a iminência, do desastre global catastrófico. A compreensão se limita a mente consciente, não despertando uma reação visceral de medo. Falta-nos uma sensação intuitiva, um instinto, que diga quando é que Gaia corre perigo.

Para que haja uma efetiva modificação no modo de pensar, é necessário um "processo de conscientização", definido por Carli (2012, p. 141) como o meio pelo qual um indivíduo passa a respeitar outro indivíduo, como ser humano, independentemente de raça, crença, cultura, política, situação socioeconômica e outras individualidades, tornando-o capaz de compreender o mundo em todos os seus aspectos e possibilitando-lhe, dessa forma, a criação de uma nova mentalidade.

Um dos objetivos primordiais da educação ambiental é formar cidadãos ativos, capazes de promover o desenvolvimento sustentável em todos os compartimentos de uma sociedade. Pela ação da sociedade conscientizada e de organizações engajadas, é possível se visualizar um futuro onde a educação ambiental seja prioridade em todas as ações governamentais. Assim, trata-se de um processo pedagógico participativo permanente e grandioso, capaz de formar cidadãos críticos sobre a problemática ambiental.

Demonstrada como pode ser afirmada a responsabilidade socioambiental por parte da sociedade, passa-se ao tópico seguinte como uma das formas de responsabilidade estatal na questão.

\section{TRIBUTAÇÃO AMBIENTAL}

Como visto anteriormente, a preocupação com um meio ambiente sadio insere-se na $\mathrm{CF} / 88$, como direito fundamental à vida digna e, sendo garantia a ser protegida pelo Estado, cabe-lhe a adoção de políticas públicas para proteção do meio ambiente.

Entre os instrumentos econômicos usados pelo Estado para a preservação do meio ambiente, indiscutivelmente, encontra-se o tributo. Tradicionalmente, os tributos assumem uma dimensão fiscal, aqueles arrecadados pelo Estado, por meio de intervenção na sociedade, para custear suas despesas. Em outros termos, trata-se de fonte de receita pública empregada pelo Estado em sua atividade financeira.

Por outro lado, quando a instituição de uma espécie tributária se dá com uma finalidade que vai além da arrecadação, sendo indutora ou coibidora de comportamentos. $\mathrm{O}$ que caracteriza a extrafiscalidade é justamente essa possibilidade de estimular condutas nos sujeitos passivos. 
A diferença entre fiscalidade e extrafiscalidade vem bem delineada por Raimundo Bezerra Falcão (1981, p. 118):

\begin{abstract}
Considerando a tributação como ato ou efeito de tributar, ou ainda, como o conjunto dos tributos, podemos afirmar que: a) a tributação se diz fiscal enquanto objetiva retirar do patrimônio dos particulares os recursos pecuniários - ou transformáveis em pecúnia - destinados às necessidades públicas do Estado; b) tributação extrafiscal é o conceito que decorre do de tributação fiscal, levando a que entendamos extrafiscalidade como atividade financeira que o Estado desenvolve sem o fim precípuo de obter recursos para seu erário, mas sim com vistas a ordenar a economia e as relações sociais, sendo, portanto, conceito que abarca, em sua amplitude, extensa gama de opções e que tem reflexos não somente econômicos e sociais, mas também políticos [...]
\end{abstract}

No ponto, registre-se o posicionamento da Professora Regina Helena Costa (2012, p.

66):

\begin{abstract}
A extrafiscalidade, por sua vez, consiste no emprego de instrumentos tributários para o atingimento de finalidades não arrecadatórias, mas, sim, incentivadoras ou inibitórias de comportamentos, com vista à realização de outros valores, constitucionalmente comtemplados.

O conteúdo potencial da extrafiscalidade é extremamente amplo, porquanto a Constituição da República contempla um número muito grande de valores e objetivos a que se subordina o Estado brasileiro.
\end{abstract}

O tributo ambiental poderá surgir com a finalidade fiscal objetivando corrigir comportamentos atentatórios ao meio ambiente, através do provimento de receita pública que para tal fim seja empregada. Entretanto, sua característica extrafiscal revela-se como mais eficaz na consecução da sustentabilidade ambiental. Tal fato constata-se em função de que, por meio da extrafiscalidade, é possível induzir condutas que se identifiquem com a proteção, preservação e promoção do meio ambiente.

Nesse último sentido, portanto, o tributo ambiental deve ser vislumbrado como um instrumento de intervenção na atividade econômica, pela qual o Estado se vale para a constituição de uma cidadania ambiental que garanta uma proteção às gerações presentes e futuras. A agregação do caráter ambiental a um tributo extrafiscal pode resultar em incentivos a toda a cadeia produtiva, derivando uma adaptação de seus processos, comportamentos e hábitos, com vistas à utilização mais eficiente e equilibrada dos recursos naturais.

Observa-se então, que a tributação ambiental consiste em um instrumento de que o Estado pode se valer para intervir no domínio econômico, de forma a incentivar ou não comportamentos e induzir os agentes econômicos na adoção de condutas ambientalmente 
sustentáveis. A aplicação do tributo ambiental não visa punir o descumprimento de um comando normativo, mas sim, diante de uma atividade econômica que possa trazer algum dano ao meio ambiente, proceder a um ajuste buscando a sua realização de forma menos danosa possível.

Nesse sentido, pode-se mencionar a importância da educação ambiental, tratada no tópico anterior. Sob o aspecto da extrafiscalidade, o tributo ambiental se apresenta de fato como aquele sugere ou incentiva a adoção de atitudes ecologicamente equilibradas, por meio da instituição de incentivos fiscais em prol da sustentabilidade. Nesse foco, observa-se a presença do princípio ambiental da precaução, positivado no art. $4^{\circ}$, incisos I, III e IV da Lei 6.938/1981 e consignado no art.225, caput e $\$ 1^{\circ}$, incisos I, II, V e VI. Esse princípio, em linhas gerais, por não ter espaço nesse estudo, alicerça-se na possibilidade de evitar a deterioração ambiental. A prevenção importa na antecedência do fato ambiental danoso (VALADARES, 2015).

Contudo, pode-se observar também na tributação ambiental o caráter da fiscalidade. Nessa esteira de raciocínio, leciona o Professor Celso Antonio Pacheco Fiorillo (2010, p. 56):

\footnotetext{
Ocorre que em determinadas situações, o Estado decide direcionar o comportamento dos contribuintes para penalizar o poluidor, incentivar a produção ou mesmo a comercialização de determinados produtos, desincentivar o consumo de tabaco ou de bebidas alcoólicas, incentivar a proteção do meio ambiente, desestimular a manutenção de propriedades que se afastem de sua função social etc. [...].
}

Nesse aspecto, é necessário se admitir que a tributação ambiental também tem fundamento no princípio do poluidor-pagador, previsto no $\$ 3^{\circ}$ do art. $225 \mathrm{da} \mathrm{CF} / 88$, impondo ao poluidor a responsabilidade pela reparação dos danos causados ao meio ambiente. Esse princípio busca evitar que a repercussão econômica da poluição, tida como o custo de sustentação do ambiente sadio, recaia sobre a coletividade. Ainda, impõe que os agentes causadores da poluição arquem com a responsabilidade pelo pagamento das despesas estatais relacionadas com a prevenção e a recuperação de danos ambientais.

O princípio do poluidor-pagador se caracteriza, assim, como princípio atuante principalmente em momento posterior à ocorrência de prejuízos causados à coletividade. Assim, faz-se necessário primeiramente poluir, para depois arcar com os custos ambientais (VALADARES, 2015).

A partir dessa lógica, o tributo recolhido aos cofres estatais com base nesse princípio possui destino certo: financiar os custos do Estado com a defesa ou, especialmente, com a 
recuperação do meio ambiente. As taxas e as contribuições, então, por serem tributos com despesa predestinada, seriam mais propícios ao emprego desse princípio. Segundo Tôrres (2005, p. 136), existe a compatibilidade das contribuições, especificamente a de intervenção sobre domínio econômico (Cide), à defesa do meio ambiente.

De fato, como se perceberá no tópico seguinte, a Cide tem como fundamento, indubitavelmente, o princípio do poluidor-pagador, especialmente porque apenas alguns setores econômicos poluidores seriam abarcados por sua tributação, e toda a receita ali arrecadada seria revertida para o financiamento de projetos ambientais vinculados ao próprio ramo causador da poluição (VALADARES, 2015).

\title{
4 CONSIDERAÇÕES SOBRE A CONTRIBUIÇÃO DE INTERVENÇÃO NO DOMÍNIO ECONÔMICO INCIDENTE SOBRE OS COMBUSTÍVEIS
}

A Contribuição de Intervenção no Domínio Econômico, de competência da União, está prevista na Constituição Federal de 1988, em seu art. 149:

\begin{abstract}
Art. 149. Compete exclusivamente à União instituir contribuições sociais, de intervenção no domínio econômico e de interesse das categorias profissionais ou econômicas, como instrumento de sua atuação nas respectivas áreas, observado o disposto nos arts. 146, III, e 150, I e III, e sem prejuízo do previsto no art. $195, \S 6^{\circ}$, relativamente às contribuições a que alude o dispositivo.
\end{abstract}

Em relação, ainda, ao art. 149 da Constituição Federal de 1988, em seu §2º, incisos I, II, III, aplicam-se às Cide's, juntamente com as contribuições sociais, as seguintes regras:

I - não incidirão sobre as receitas decorrentes de exportação; (Incluído pela Emenda Constitucional $\mathrm{n}^{\mathrm{o}} 33$, de 2001)

II - poderão incidir sobre a importação de petróleo e seus derivados, gás natural e seus derivados e álcool combustível; (Incluído pela Emenda Constitucional no 33, de 2001)

II - incidirão também sobre a importação de produtos estrangeiros ou serviços; (Redação dada pela Emenda Constitucional no 42, de 19.12.2003)

III - poderão ter alíquotas: (Incluído pela Emenda Constitucional no 33, de 2001)

a) ad valorem, tendo por base o faturamento, a receita bruta ou o valor da operação e, no caso de importação, o valor aduaneiro; (Incluído pela Emenda Constitucional $\mathrm{n}^{\mathbf{o}} 33$, de 2001)

b) específica, tendo por base a unidade de medida adotada. (Incluído pela Emenda Constitucional $\mathrm{n}^{\circ} 33$, de 2001) 
Segundo Amaral (2007, p. 185-186), a combinação dos art. 149 e 170, VI, da CF/88 faz nascer a Cide de caráter ambiental, que assumirá natureza de tributo vinculado por destinar sua arrecadação, diretamente, ao desenvolvimento de política de proteção ambiental no setor econômico que motivou sua instituição. De algum modo, essa contribuição interventiva de natureza ambiental converte o contribuinte em destinatário dos recursos desse tributo, pois a receita tributária é revertida para financiar projetos de proteção ambiental vinculados ao setor econômico que gerou danos ambientais.

A Carta Constitucional brasileira de 1988 inseriu, em seu próprio corpo, por meio da Emenda Constitucional 33/2001, elementos ambientais na previsão de instituição de Cide relativa às atividades de importação ou comercialização de petróleo e seus derivados, gás natural e seus derivados e álcool combustível, ao determinar que parte dos recursos arrecadados seja destinada ao financiamento de projetos ambientais relacionados com a indústria do petróleo e do gás, em norma expressa no art. 177, § 4º, II, 'b', CF/88 (VALADARES, 2015):

Art. 177. [...] $\S 4^{\circ}$. A lei que instituir contribuição de intervenção no domínio
econômico relativa às atividades de importação ou comercialização de petróleo e
seus derivados, gás natural e seus derivados e álcool combustível deverá atender aos
seguintes requisitos: [...] II - os recursos arrecadados serão destinados: [...] b) ao
financiamento de projetos ambientais relacionados com a indústria do petróleo e do
gás; (Incluído pela Emenda Constitucional n. 33 , de 2001); [...]

A referida Cide foi instituída pela Lei 10.336/2001, mas os critérios e as diretrizes para a aplicação do produto de sua arrecadação somente foram trazidos pela Lei 10.636/2002. A incidência da contribuição em apreço ocorre sobre a importação e a comercialização de gasolina, diesel e respectivas correntes; querosene de aviação e derivativos, óleos combustíveis, gás liquefeito de petróleo (GLP), inclusive o derivado de gás natural e de nafta; álcool etílico combustível.

Segundo o inciso III do $\S 1^{\circ}$ do art. $1^{\circ}$ da Lei $n^{o} 10.336 / 2001$, o produto da arrecadação da Cide Combustível deverá ser destinado, dentre outros, ao financiamento de Programas de Infraestrutura de Transportes, o que confirma sua adequação ao princípio do poluidor-pagador:

Art. $1^{\circ}$ Fica instituída a Contribuição de Intervenção no Domínio Econômico incidente sobre a importação e a comercialização de petróleo e seus derivados, gás natural e seus derivados, e álcool etílico combustível (Cide), a que se refere os arts. 
149 e 177 da Constituição Federal, com a redação dada pela Emenda Constitucional no 33 , de 11 de dezembro de 2001.

$\S 1^{\circ} \mathrm{O}$ produto da arrecadação da Cide será destinado, na forma da lei orçamentária, ao:

III - financiamento de programas de infraestrutura de transportes.

Ainda, de acordo com o art. $4^{\circ}$ da Lei 10.636/2002, os projetos ambientais a que se referem a CF/88 e a Lei 10.336/2001, a serem administrados pelo Ministério do Meio Ambiente (MMA), abrangerão: (i) o monitoramento, o controle e a fiscalização de atividades efetiva ou potencialmente poluidoras; (ii) o desenvolvimento de planos de contingência locais e regionais para situações de emergência; (iii) o desenvolvimento de estudos de avaliação e diagnóstico e de ações de Educação Ambiental em áreas ecologicamente sensíveis ou passíveis de impacto ambiental; (iv) o apoio ao desenvolvimento de instrumentos de planejamento e proteção de Unidades de Conservação costeiras, marinhas e de águas interiores; (v) o fomento a projetos voltados à preservação, revitalização e recuperação ambientais em áreas degradadas pelas atividades relacionadas à indústria de petróleo e de seus derivados e do gás e seus derivados; (vi) o fomento a projetos voltados à gestão, preservação e recuperação das florestas e dos recursos genéticos em áreas de influência de atividades relacionadas à indústria de petróleo e de seus derivados e do gás e seus derivados; e (vii) o fomento a projetos voltados à produção de biocombustíveis, com foco na redução dos poluentes relacionados com a indústria de petróleo, gás natural e seus derivados.

Com relação à Cide combustível, como sua incidência se faz justamente na atividade econômica voltada para a indústria do combustível, guarda total coerência a utilização desses recursos para a proteção a danos ambientais possíveis causados por essa atividade, vez que os danos ocasionados com a exploração do petróleo são de proporção imprevisível. No Brasil, não há um fundo específico para prevenir e recuperar danos ou passivos ambientais em áreas afetadas por hidrocarbonetos. Esse fundo seria custeado pelos agentes que exercem a atividade relacionada com a indústria do petróleo (BRUNO; BRITO NETO, 2015).

Como visto acima, o princípio poluidor- pagador vem expresso no $\S 3^{\circ}$ do art. 225 da $\mathrm{CF} / 88$, e já residia no art. $4^{\circ}$, VII da Lei $\mathrm{n}^{\circ}$. 6.938/81, como sendo um dos objetivos da Política Nacional do Meio Ambiente. A responsabilidade do poluidor, inclusive, se faz de forma objetiva, independente de culpa, nos termos do art. $14, \S 1^{\circ}$ da citada lei. Outro princípio que reforça a ação preventiva dos danos ambientais passíveis de serem causados pela indústria do petróleo é o princípio usuário-pagador, segundo o qual o usuário que utiliza um bem ambiental paga para ter direito a essa contraprestação, podendo explorar um 
determinado recurso natural. Por este princípio, pode-se fundamentar a cobrança daqueles que utilizam, em larga escala, os recursos naturais em atividades geradoras de riqueza, visto que se está utilizando um patrimônio da coletividade em interesse particular (BELTRÃO, 2009).

A análise a ser feita, nos termos do título do tópico, deve balizar-se na real destinação feita no caso concreto, dos recursos recolhidos através do tributo em exame e sua aplicação nos Programas de Infraestrutura de Transportes pelo Brasil. Avalia-se a alocação dos valores arrecadados e a correspondente aplicação a partir das reais necessidades dentro do setor de transporte coletivo, acreditando que com um repasse mais igualitário entre os entes federativos esta deficiência estaria preenchida.

Os Estados e o Distrito Federal irão receber da União $29 \%$ do total dos recursos arrecadados com a Cide Combustível (inciso III, art.159, CF). Esses percentuais terão de ser aplicados, imperativamente, no financiamento de programas de infraestrutura de transportes. Dos $29 \%$ dos recursos que cabe a cada Estado, 25\% serão destinados aos seus Municípios para igualmente, serem aplicados em infraestrutura de transportes (art. $1^{\circ}-\mathrm{B}$, da Lei $\mathrm{n}^{\circ}$ $10.336 / 2001)$.

Ressalta-se que, em 2012, o Governo Federal reduziu a zero o valor da CIDE para a Gasolina e o Diesel, em virtude de a Petrobrás ter anunciado um então aumento de 7,83\% no preço da Gasolina e de 3,94\% no valor do Diesel. O escopo dessa medida era francamente oportunista, pois visava exclusivamente evitar que os aumentos não chegassem aos postos de gasolina e atingissem assim o consumidor, contendo, dessa maneira, também a alta da inflação.

O objetivo do Governo era paralisar o impacto do acréscimo nos preços das refinarias para o consumidor. Porém, a alíquota zero aplicada à Cide Combustível pelo Governo veio a amparar mais ainda os combustíveis fósseis em relação aos combustíveis renováveis. Por outro lado, desprestigiou e massacrou a indústria sucroalcooleira nacional. Com esse gargalo de mercado implementado pelo Governo, o etanol deixou de competir, já que o preço da gasolina baixou em virtude da mencionada alíquota zero da Cide. Não se pode esquecer que a Cide Combustível incide nos combustíveis fósseis e não no etanol. Existindo uma redução na diferença tributária entre a gasolina e o etanol, este último perde competitividade e capacidade de desenvolvimento em tecnologia.

Ao invés de o Governo proteger e amparar o desenvolvimento e o estímulo dos produtos renováveis dentro da sociedade brasileira implanta uma política retrógrada de apoio a matrizes energéticas fósseis, visivelmente fadadas ao declínio e à extinção. Além disso, 
ofende princípios e normas constitucionais de clara inteligência a busca de um meio ambiente sustentável, que dão harmonia aos fatores de produção e a uma política de consumo ecologicamente correta, pensando nas gerações futuras que irão usufruir do ecossistema, ou seja, o desenvolvimento sustentável.

Outro grave problema da falta de compromisso do Governo Federal com a questão da sustentabilidade ambiental, diz respeito ao foco nos produtos fósseis, desonerando sua tributação. Com essa postura, o Governo incentiva a indústria automobilística, e o próprio consumidor a comprar veículos, com incentivos fiscais e baixas taxas de juros bancários com essa finalidade, alcançando um aumento desregrado na venda de veículos automotores através de uma ilusória antecipação da pretensão de compra do consumidor.

O Poder Público não deveria improvisar uma opção puramente política, ferindo os anseios da Constituição e agredindo programas e valores que transcendem o imediatismo de um governo. Promover artificialmente a baixa dos combustíveis fósseis, manipulando o mercado e aniquilando a concorrência, ao invés de optar por estimular e promover a proteção do meio ambiente através de uma matriz energética limpa, não pode ser o modelo de desenvolvimento do Brasil.

A União deveria tentar refrear todas essas aberrações, desonerando os tributos gradativamente em relação aos produtos fósseis, como, por exemplo, o PIS e a COFINS do óleo diesel utilizado no transporte público e energia elétrica utilizada pelo metrô. Além disso, realizaria maiores repasses da Cide Combustível aos Estados. Os estados transfeririam maiores percentuais aos municípios e com isso, possibilitaria uma redução do ICMS, em relação a itens francamente ligados ao transporte público. Os municípios, do mesmo modo, poderiam contribuir reduzindo o ISS, quando se tratasse de empresas de transporte coletivo.

O repasse integral da Cide Combustível aos Estados e Municípios pela União seria uma possibilidade. Não há justificativa para o repasse por parte da União ser de apenas $29 \%$ da Cide Combustível para os Estados, e estes repassarem somente 25\% para os Municípios, devendo ser ressaltado que a maior parte dos problemas de infraestrutura de transporte está nos Municípios.

Dito isso, resta a inquirição acerca de onde a União aproveita o restante do produto da arrecadação da Cide Combustível, verificando-se a falta de conservação da infraestrutura rodoviária brasileira. 


\section{CONCLUSÃO}

A preocupação com um meio ambiente sadio insere-se na $\mathrm{CF} / 88$, como direito fundamental à vida digna e, sendo garantia a ser protegida pelo Estado, cabe-lhe a adoção de políticas públicas para proteção do meio ambiente.

Entre os instrumentos econômicos usados pelo Estado para a preservação do meio ambiente, indiscutivelmente, encontra-se o tributo. Nesse sentido, o tributo ambiental poderá surgir com a finalidade fiscal objetivando corrigir comportamentos atentatórios ao meio ambiente, através do provimento de receita pública que para tal fim seja empregada. Entretanto, sua característica extrafiscal revela-se como mais eficaz na consecução da sustentabilidade ambiental. Tal fato constata-se em função de que, por meio da extrafiscalidade, é possível induzir condutas que se identifiquem com a proteção, preservação e promoção do meio ambiente.

Nesse último sentido, portanto, o tributo ambiental deve ser vislumbrado como um instrumento de intervenção na atividade econômica, pela qual o Estado se vale para a constituição de uma cidadania ambiental que garanta uma proteção às gerações presentes e futuras. A agregação do caráter ambiental a um tributo extrafiscal pode resultar em incentivos a toda a cadeia produtiva, derivando uma adaptação de seus processos, comportamentos e hábitos, com vistas à utilização mais eficiente e equilibrada dos recursos naturais. Nesse sentido, pode-se mencionar a importância da educação ambiental.

Nesse aspecto, o tributo ambiental se apresenta de fato como aquele sugere ou incentiva a adoção de atitudes ecologicamente equilibradas, por meio da instituição de incentivos fiscais em prol da sustentabilidade. Nesse foco, observa-se a presença do princípio ambiental da precaução, positivado no art. $4^{\circ}$, incisos I, III e IV da Lei 6.938/1981 e consignado no art.225, caput e $\S 1^{\circ}$, incisos I, II, V e VI. Esse princípio, em linhas gerais, tem como fundamento a possibilidade de evitar a deterioração ambiental. A prevenção antecede a ocorrência do fato ambiental danoso.

Sob um outro ponto de vista, é necessário se admitir que a tributação ambiental também tem fundamento no princípio do poluidor-pagador, previsto no $\$ 3^{\circ}$ do art. 225 da $\mathrm{CF} / 88$. Esse princípio busca evitar que a repercussão econômica da poluiçãorecaia sobre a coletividade. Ainda, impõe que os agentes causadores da poluição arquem com a responsabilidade pelo pagamento das despesas estatais relacionadas com a prevenção e a 
recuperação de danos ambientais. Faz-se, portanto, necessário primeiramente poluir, para depois arcar com os custos ambientais.

A partir dessa lógica, o tributo recolhido aos cofres estatais com base nesse princípio possui destino certo: financiar os custos do Estado com a defesa ou, especialmente, com a recuperação do meio ambiente. Nesse sentido, existe a compatibilidade das contribuições, especificamente a de intervenção sobre domínio econômico (Cide), prevista a partir de uma combinação dos art. 149 e 170 da CF/88, à defesa do meio ambiente, já que apenas alguns setores econômicos poluidores seriam abarcados por sua tributação, e toda a receita ali arrecadada seria revertida para o financiamento de projetos ambientais vinculados ao próprio ramo causador da poluição.

A Emenda Constitucional 33/2001 trouxe a previsão de instituição de Cide relativa às atividades de importação ou comercialização de petróleo e seus derivados, gás natural e seus derivados e álcool combustível, ao determinar que parte dos recursos arrecadados seja destinada ao financiamento de projetos ambientais relacionados com a indústria do petróleo e do gás, em norma expressa no art. 177, $\S 4^{\circ}$, II, 'b', CF/88.

A referida Cide foi regulamentada pela Lei 10.336/2001, mas os critérios e as diretrizes para a aplicação do produto de sua arrecadação somente foram trazidos pela Lei 10.636/2002. A incidência da contribuição em apreço ocorre sobre a importação e a comercialização de gasolina, diesel e respectivas correntes; querosene de aviação e derivativos, óleos combustíveis, gás liquefeito de petróleo (GLP), inclusive o derivado de gás natural e de nafta; álcool etílico combustível.

Segundo o inciso III do $\S 1^{\circ}$ do art. $1^{\circ}$ da Lei $n^{\circ} 10.336 / 2001$, o produto da arrecadação da Cide Combustível deverá ser destinado, dentre outros, ao financiamento de Programas de Infraestrutura de Transportes, o que confirma sua adequação ao princípio do poluidor-pagador. Contudo, no Brasil, não há um fundo específico para prevenir e recuperar danos ou passivos ambientais em áreas afetadas por hidrocarbonetos.

Ao longo do trabalho, foi feito uma análise com base na real destinação feita dos recursos recolhidos através do tributo em exame e sua aplicação nos Programas de Infraestrutura de Transportes pelo Brasil.

De acordo o inciso III do art. 159 da CF, os Estados e o Distrito Federal irão receber da União $29 \%$ do total dos recursos arrecadados com a Cide Combustível (inciso III, art.159, $\mathrm{CF}$ ). Esses percentuais terão de ser aplicados, imperativamente, no financiamento de 
programas de infraestrutura de transportes. Dos $29 \%$ dos recursos que cabe a cada Estado, 25\% serão destinados aos seus Municípios para igualmente, serem aplicados em infraestrutura de transportes ( $\operatorname{art} .1^{\circ}-\mathrm{B}$, da Lei $\mathrm{n}^{\circ} 10.336 / 2001$ ).

Contudo, vislumbra-se o repasse por parte da União de apenas $29 \%$ da Cide Combustível para os Estados, e estes repassam somente 25\% para os Municípios, devendo-se ressaltar que a maior parte dos problemas de infraestrutura de transporte está nos Municípios. Assim, acredita-se que um repasse da Cide mais igualitário em apreço entre os entes federativos supriria a deficiência da infraestrutura de transportes brasileira. 


\section{REFERÊNCIAS}

AMARAL, Paulo Henrique. Direito Tributário Ambiental. São Paulo: Revista dos Tribunais, 2007.

BECK, Ulrich. Sociedade de risco: rumo a uma outra modernidade. Tradução Sebastião Nascimento. São Paulo: ed. 34, 2010.

BELTRÃO, A. F. G. Curso de direito ambiental. São Paulo: Método, 2009.

BRUNO, Flávio Marcelo Rodrigues; BRITO NETO, José Gomes. As contribuições sociais de intervenção no domínio econômico como instrumentos de políticas públicas para o equilíbrio sócio ambiental. In: Direito e sustentabilidade [Recurso eletrônico on-line] organização CONPEDI/UFS; Coordenadores Consuelo Yatsuda Moromizato Yoshida, Raquel Fabiana Lopes Sparemberger, Rosângela Lunardelli Cavallazzi - Florianópolis: CONPEDI, 2015.

CAPRA, Fritjof. As Conexões Ocultas - Ciência para uma Vida Sustentável. São Paulo: Pensamento-Cultrix, 2005.

CARLI, Vilma Maria Inocêncio. A obrigação legal de preservar o meio ambiente. Campinas: Servanda Editora, 2012.

COSTA, Regina Helena. Curso de Direito Tributário - Constituição e Código Tributário Nacional. São Paulo: Saraiva, 2012.

FALCÃO, Raimundo Bezerra. Tributação e mudança social. Rio de Janeiro: Forense, 1981.

FIORILLO, Celso Antonio Pacheco; FERREIRA, Renata Marques. Direito Ambiental Tributário. São Paulo: Saraiva, 2010.

LOVELOCK, James. A Vingança de Gaia. Rio de Janeiro: Intrínseca, 2006.

SARLET, Ingo Wolfgang; FENSTERSEIFER, Tiago. Direito Constitucional Ambiental Constituição, Direitos Fundamentais e Proteção do Ambiente. São Paulo: Revista dos Tribunais, 2014.

SILVA, José Afonso da. Direito Ambiental Constitucional. São Paulo: Malheiros Editores, 2004.

TÔRRES, Heleno Taveira. Da relação entre competências constitucionais tributária e ambiental: os limites dos chamados "tributos ambientais". In: TÔRRES, Heleno Taveira (Org.). Direito Tributário Ambiental. São Paulo: Malheiros, 2005.

VALADARES, André Garcia Leão Reis. Tributação ambiental e sua compatibilidade com o Sistema Tributário brasileiro. Revista Direito Ambiental e sociedade, v. 5, n. 1, 2015 (p. 
129-160). Disponível em: <file:///D:/Users/julianna.reis/Downloads/3209-14806-1-PB.pdf>. Acesso em: 20.09.2016.

VILLAC, Teresa. Direito internacional ambiental como fundamento principiológico e de juridicidade para as Licitações sustentáveis no Brasil. In: SANTOS, Murillo Giorda; VILLAC, Teresa (Coord.). Licitações e contratações públicas sustentáveis. 2. ed. Belo Horizonte: Fórum, 2015. p. 43-68. 